\title{
Pavimentos flexíveis: estudo de caso da marginal oeste da rodovia BR-010, região metropolitana do município de Palmas/TO
}

Com a crescimento populacional e econômica, a necessidade de expansão do setor de transporte se torna essencial. No Brasil o principal modo de transportes de cargas e passageiros é o rodoviário, com isso, é imprescindível que o projeto bem como a execução dos pavimentos seja realizado com estudos e técnicas adequadas. Os pavimentos flexíveis, objetivo deste estudo, possuem requisitos técnicos que precisam ser atendidos para a sua eficácia. A escolha da mistura asfáltica e dos materiais que compõe as camadas deve ser compatível com o tipo de solicitação exigidas em projeto. Para que um pavimento disponha de um desempenho operacional estável, é de fundamental importância o uso correto das espessuras das camadas, uma vez que uma camada executada de forma correta prolonga a vida útil do pavimento, melhora as condições de trafegabilidade e reduz os custos de manutenção dos veículos. O presente estudo tem por objetivo verificar a qualidade do projeto executado na Marginal Oeste da BR-010 no perímetro urbano de Palmas/TO, e averiguar se o projeto executado inicialmente obedecia às normas mínimas exigidas pelos órgãos competentes, no que tange espessuras mínimas, bem como diagnosticar se o pavimento que hoje existente suporta a solicitação atual.

\section{Flexible pavements: case study of the west marginal BR-010, metropolitan region of the municipality of Palmas/TO}

\begin{abstract}
With the populational and economic growth, the need to expand the transport sector becomes essential. In Brazil, the main way of transporting passengers and cargo is by road, so, it's indispensable that the project and execution of the pavement is done with adequate studies and techniques. The flexible pavements, objective of this study, have technical requirements that needs to be met for their effectiveness. The chosen asphaltic mixture and the materials for the layers must be compatible with the requirements of the project. For a stable operational performance of the pavement, it's important that the thickness of the layers are used correctly, since an correctly executed layer boosts the pavement's lifespan, makes traffic conditions better and reduce the costs of vehicle maintenance. The Objective of this study is to verify the quality of the executed project on the West Margin of the BR-010 in Palmas/TO urban perimeter, and to find out if the initial project meets the minimal regulations required by the regulatory bodies, on minimal thickness, and also diagnose if the existent pavement supports the current requirements.
\end{abstract}

Keywords: Flexible Paviments; Flexible Paviment Projects; Paviment Restoration.

Topic: Engenharia Urbana

Reviewed anonymously in the process of blind peer.

Taís da Silva Costa

Instituto Tocantinense Presidente Antônio Carlos Porto, Brasil

http://lattes.cnpq.br/7518351539063596

engtaiscosta1@gmail.com

Flávio Vieira da Silva Júnior

Faculdade Presidente Antônio Carlos, Brasil

http://lattes.cnpq.br/2211436659738090

flaviovisiju@gmail.com
Received: 14/06/2018

Approved: 24/09/2018
Referencing this:

COSTA, T. S.; SILVA JÚNIOR, F. V.. Pavimentos flexíveis: estudo de caso da marginal oeste da rodovia BR-010, região metropolitana do município de Palmas/TO. Engineering Sciences, v.6, n.2, p.43-52, 2018. DOI: http://doi.org/10.6008/CBPC2318-3055.2018.002.0005 


\section{INTRODUÇÃO}

Com o crescimento populacional, surge à necessidade de conquistar novos territórios e interligar regiões longínquas, com o intuito de promover maior interação entre os povos, além de facilitar o comércio entre regiões vizinhas. Deste modo originou-se o principal meio de transporte utilizado atualmente no Brasil, o modal rodoviário. A malha rodoviária brasileira é constituída por pavimentos rígidos e flexíveis, o primeiro apresenta um maior custo de implantação, mas de maior resistência mecânica, o segundo é predominante no pavimento nacional, oferece um menor custo de implantação.

Apesar da importância da rede rodoviária, apenas uma pequena porcentagem encontra-se de maneira adequada para receber as solicitações impostas pelo tráfego, devido a projetos elaborados ou executados de forma incorreta, ou até mesmo à falta ou falha na conservação das vias. Para o dimensionamento dos pavimentos flexíveis é preciso seguir alguns requisitos, tais como: padrões de qualidade, estrutural e funcional, com finalidade de evitar uma degradação precoce nas rodovias. Esses requisitos são regulamentados Departamento Nacional de Infraestrutura de Transporte (DNIT) principal órgão federal que desempenham funções quanta à construção, conservação e operacional da infraestrutura federal.

Nesta pesquisa pretende-se fazer um estudo sobre o trafego e as condições de rolamento a marginal oeste a BR-010 de Palmas/TO. Para a determinar as espessuras das camadas, foram realizados ensaios físicos e mecânicos para análise das características do solo estudado, além de determinar o volume médio diário atuante no pavimento. Após avaliar os termos citados, realizou um comparativo entre as espessuras do pavimento dimensionado com o fluxo de tráfego atual.

\section{METODOLOGIA}

Para o desenvolvimento da pesquisa e atingir o objetivo do trabalho, foi escolhido a marginal oeste a BR 010 no município de Palmas/TO. Após a escolha do objeto de estudo foram definidas as etapas para a execução dos ensaios, bem como, para a determinação do fluxo de veículos.

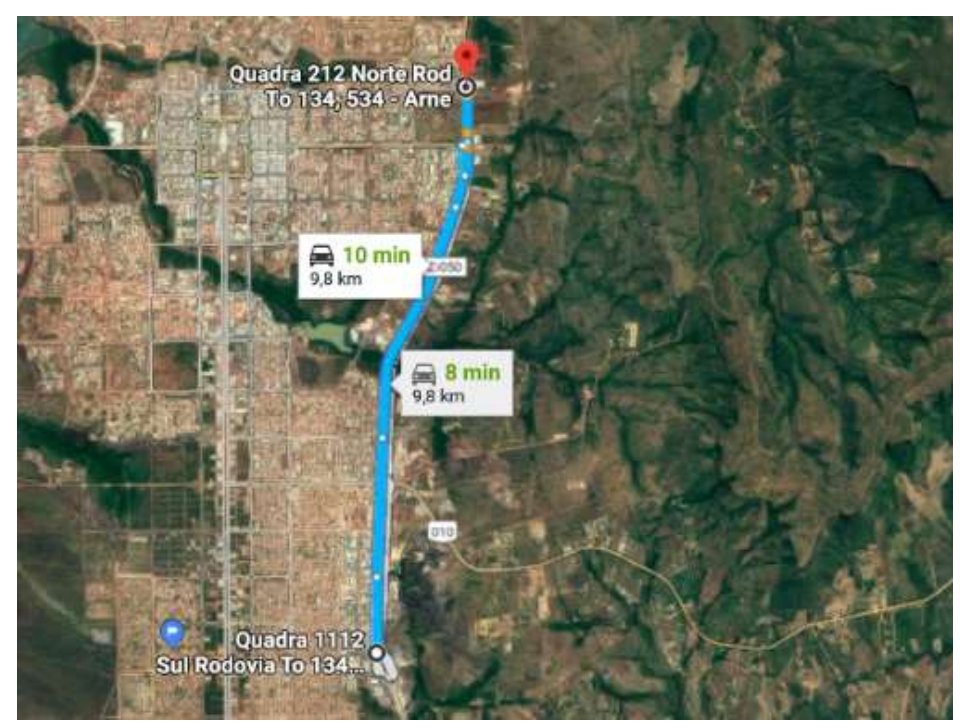

Figura 1: Localização da marginal oeste. 
Nas etapas de execução foram realizadas visitas em campo, para determinação do tipo de tráfego, além de extrair a amostra da base e do subleito para análise da qualidade do material utilizado por meio do ensaio de CBR - Califórnia Bearing Ratio, a amostra do subleito foi extraída a uma profundidade média de 0,50 cm da superfície para o ensaio mecânica mencionado anteriormente e os ensaios de Limite de Plasticidade (WP), Limite de Liquidez (WL), Massa Especifica do Solo, Análise Granulométrica e Compactação.

Todos os ensaios foram realizados no laboratório de Geotecnia e Pavimentação do Instituto Tocantinense Presidente Antônio Carlos, no período de junho a setembro de 2018. O material foi colocado para secar ao ar livre e posteriormente foi destorroado para em seguida ser utilizado na execução dos ensaios que já foram supracitados.

\section{Ensaios físicos}

A determinação dos Limite $\mathrm{s}$ de consistência foi necessário em torno de $120 \mathrm{~g}$ de material, destorroado e seco ao ar livre, que passa na peneira $40(0,42 \mathrm{~mm})$. 0 ensaio de Limite de Liquidez foi executado com o objetivo de obter a umidade pela quantidade de golpes que o solo fecha a ranhura, ou seja, passa pelo ponto de transição entre o estado plástico para o liquido. O procedimento de ensaio foi regido pela NBR 7180/1982-ABNT.

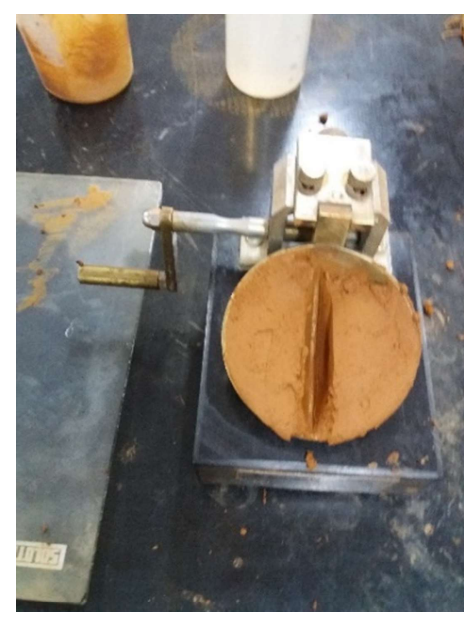

Figura 2: Limite de Liquidez.

Também foi realizado o ensaio de Limite de Plasticidade com o objetivo de determinar o teor de umidade do solo quando o mesmo passa do estado plástico para o semi-sólido, com isso determinando o menor teor de umidade quando o solo ainda se comporta como plástico, sendo importante essa informação para determinar deformabilidade do material com a presença de água. O procedimento de ensaio foi regido de acordo com a NBR 7180/1984.

A diferença entre os dois limites mencionados anteriormente obtém-se Índice de Plasticidade, esse resultado mostra o quão plástico o material é, sendo máximo para as argilas e nulos para areias. 0 ensaio de granulometria por peneiramento foi realizado com auxílio das peneiras determinadas de acordo com a NBR 7181/1988 como mostra a Figura 4, com o objetivo de classificar o solo em escalas granulométricas 
(dimensões de suas partículas) que são elas: Pedregulho: 76 a 4,8 mm; Areia: 4,8 a 0,05 mm; Silte: 0,05 a 0,005 mm; Argila: menor que 0,005 mm.

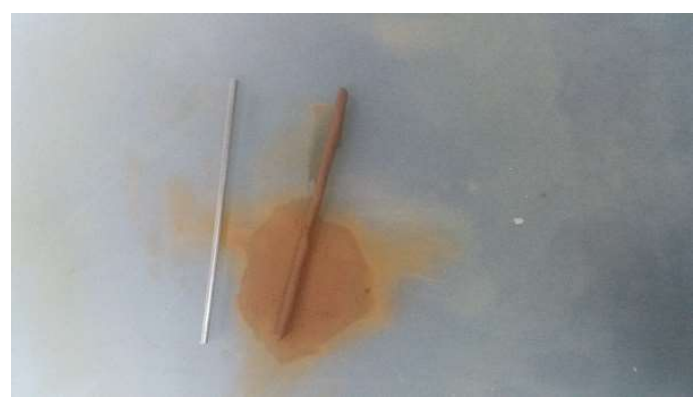

Figura 3: Limite de Plasticidades.

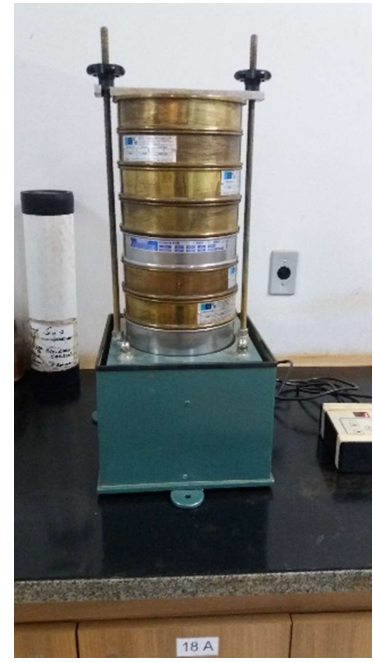

Figura 4: Ensaio de Granulometria.

Em seguida foi realizado o ensaio de sedimentação conforme exibe a Figura 5, no qual tomou cerca de $70 \mathrm{~g}$ de solo, o mesmo tem como objetivo definir a porcentagem de finos que compõem a amostra estudada. Tal como os outros ensaios, de compactação também seguiu sua respectiva norma, a NBR 7182/1988 na qual foram compactados cinco corpos de prova apresentados na Figura 6 , tanto com material do subleito quanto da base com Energia Proctor normal e intermediária respectivamente, na umidade ótima e seu respectivo peso especifico aparente seco obtido a partir das curvas de compactação.

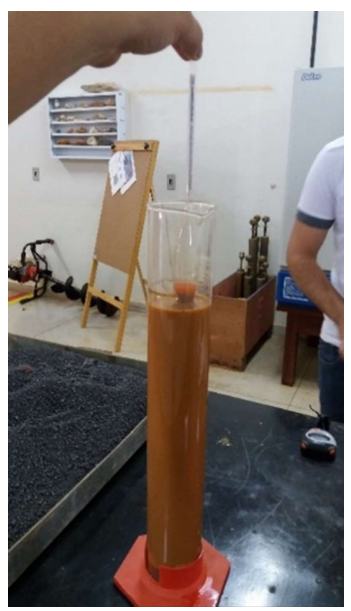

Figura 5: Ensaio de Sedimentação. 


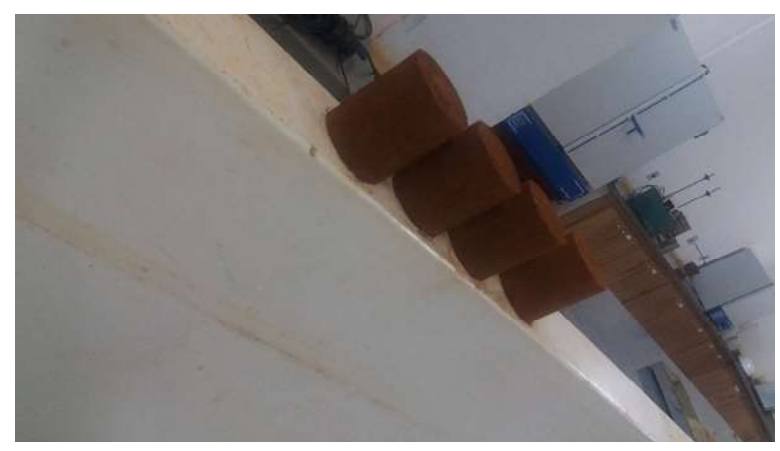

Figura 6: Ensaio de compactação.

Para o ensaio de Massa Específica, como mostra a Figura 7 foi necessário consultar a NBR 6508/1984, o procedimento foi realizado para determinar a densidade real dos grãos composto na amostra de solo.

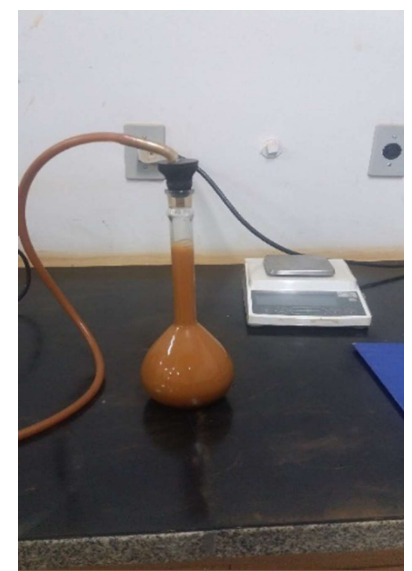

Figura 7: Ensaio de Massa Específica.

\section{Ensaios mecânicos}

Para o ensaio de CBR e Expansão foi necessário consultar a NBR 9895/2017, este ensaio é típico para o dimensionamento de rodovias, sendo um dos mais aceitáveis para avaliação das características dos solos, seja para o dimensionamento ou comportamento das camadas do pavimento. Para esse procedimento foi necessário $18 \mathrm{~kg}$ de amostra, utilizando $6 \mathrm{~kg}$ para cada corpo de prova, o material do subleito foi compactado com 12 golpes (Energia Proctor Normal) para cada uma das 5 camadas.

Em um tanque d'água foi posto para verificação da expansão, ficou imerso durante 4 dias que no final desse prazo levou para verificar a resistência a penetração do solo, para fim de obtenção do valor de CBR. A mesma ação se repetiu com o solo da base, mas utilizando uma Energia Proctor Intermediária (21 golpes) para cada uma das 5 camadas.

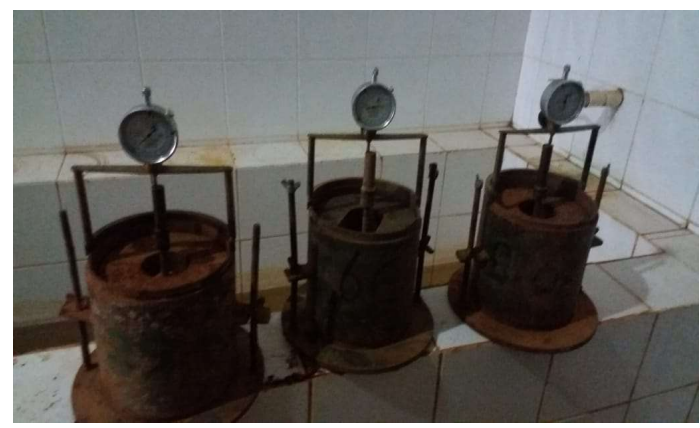

Figura 8: Ensaio de CBR e expansão para Subleito. 


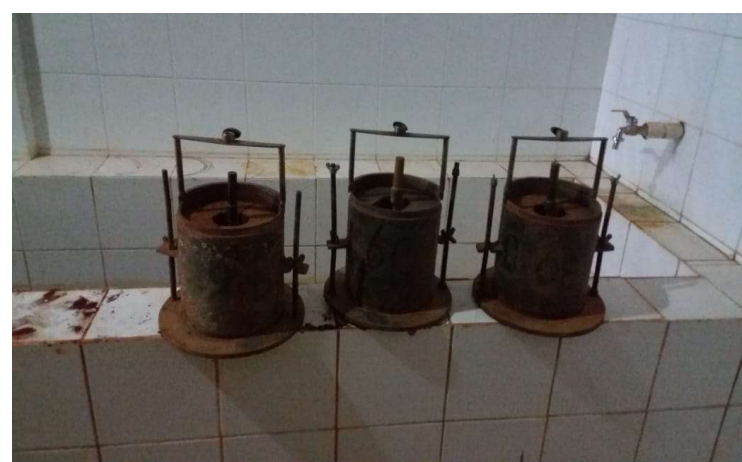

Figura 9: Ensaio de CBR e expansão para base.

\section{RESULTADOS}

\section{Classificação dos solos}

O solo ensaiado foi classificado com o auxílio dos parâmetros de ensaios de limites de consistência, analise granulométrica e índice de grupo do subleito e os resultados estão apresentados na Tabela 1. De acordo com a American Association of State Highway and Transportation Officials-AASHTO foi classificado no grupo da família A-2 (A-2-4), pedregulhos ou areias siltosas ou argilosas tendo comportamento geral para o subleito de excelente a bom.

Na classificação Highway Research Bord (HRB), os solos são divididos em grupos e subgrupos, em função da sua granulometria, índices de consistência e índice de grupo demostrados na Tabela 1, com isso o subleito foi classificado como da família A-2 e do grupo A-2-4, pedregulho e areia siltosa ou argilosa.

Tabela 1: Caracterização física para a AAHTO.

\begin{tabular}{lll}
\hline DESCRIÇÃO & RESULTADOS \\
\hline Massa específica & 2,754 & $\mathrm{~g}$ \\
\hline Peneiramento passante na peneira 10 & 99,9 & $\%$ \\
\hline Peneiramento passante na peneira 40 & 72,8 & $\%$ \\
\hline Peneiramento passante na peneira 200 & 31,4 & $\%$ \\
\hline Limite de liquidez - WL & 21,6 & $\%$ \\
\hline Limite de plasticidade - WP & 18,6 & $\%$ \\
\hline Índice de plasticidade - IP & 3 & $\%$ \\
\hline Peso especifico seco máximo- ${ }^{\text {Dd }}$ máx. & 1,82 & $\mathrm{~g} / \mathrm{cm}^{3}$ \\
\hline Umidade ótima Wót & 13 & $\%$ \\
\hline
\end{tabular}

Para classificar o solo de acordo com Sistema Unificado de Classificação dos Solos-SUCS foram utilizados os dados dos ensaios, sendo que o mesmo se baseia na qualidade da textura e plasticidade do material, com isso foi necessário utilizar a análise granulométrica e índice de consistência, com os resultados das porcentagens que passam nas peneiras como mostra a Tabela 2, obteve-se os coeficientes de uniformidade e coeficiente de curvatura, então o solo é considerado areia siltosa/SM.

De acordo com os dados apresentados na Tabela 2, por meio dos limites de consistências do solo, o mesmo também pode ser classificado conforme o Gráfico de Plasticidade idealizado pelo profo Artur Casagrande como demostra a Figura 10. Por meio desse gráfico classificamos o material do subleito, como: siltes inorgânicos de baixa compressibilidade. 
Conforme a NBR 6502/1995 por meio do ensaio de granulometria e sedimentação podemos classificar a quantidade de finos que compõe o solo, sendo $22,2 \%$ de argila e $8 \%$ de silte conforme demostrado na Tabela 3.

Tabela 2: Caracterização física para a SUCS.

\begin{tabular}{lll}
\hline DESCRIÇÃO & RESULTADOS & g \\
\hline Massa específica & 2,754 & $\%$ \\
\hline Peneiramento passante na \# 10 & 99,9 & $\%$ \\
\hline Peneiramento passante na \# 40 & 72,8 & $\%$ \\
\hline Peneiramento passante na \# 200 & 31,4 & $\%$ \\
\hline Limite de liquidez - WL & 21,6 & $\%$ \\
\hline Limite de plasticidade - WP & 18,6 & $\%$ \\
\hline Índice de plasticidade - IP & 3 & 1,82 \\
\hline Peso especifico seco máximo- ${ }^{\text {d d máx. }}$ & 13 & $\%$ \\
\hline Umidade ótima Wót & 0 & $\%$ \\
\hline Coeficiente de uniformidade - CU & 0,0012 & $\%$ \\
\hline Coeficiente de curvatura - CC & & $\%$ \\
\hline
\end{tabular}

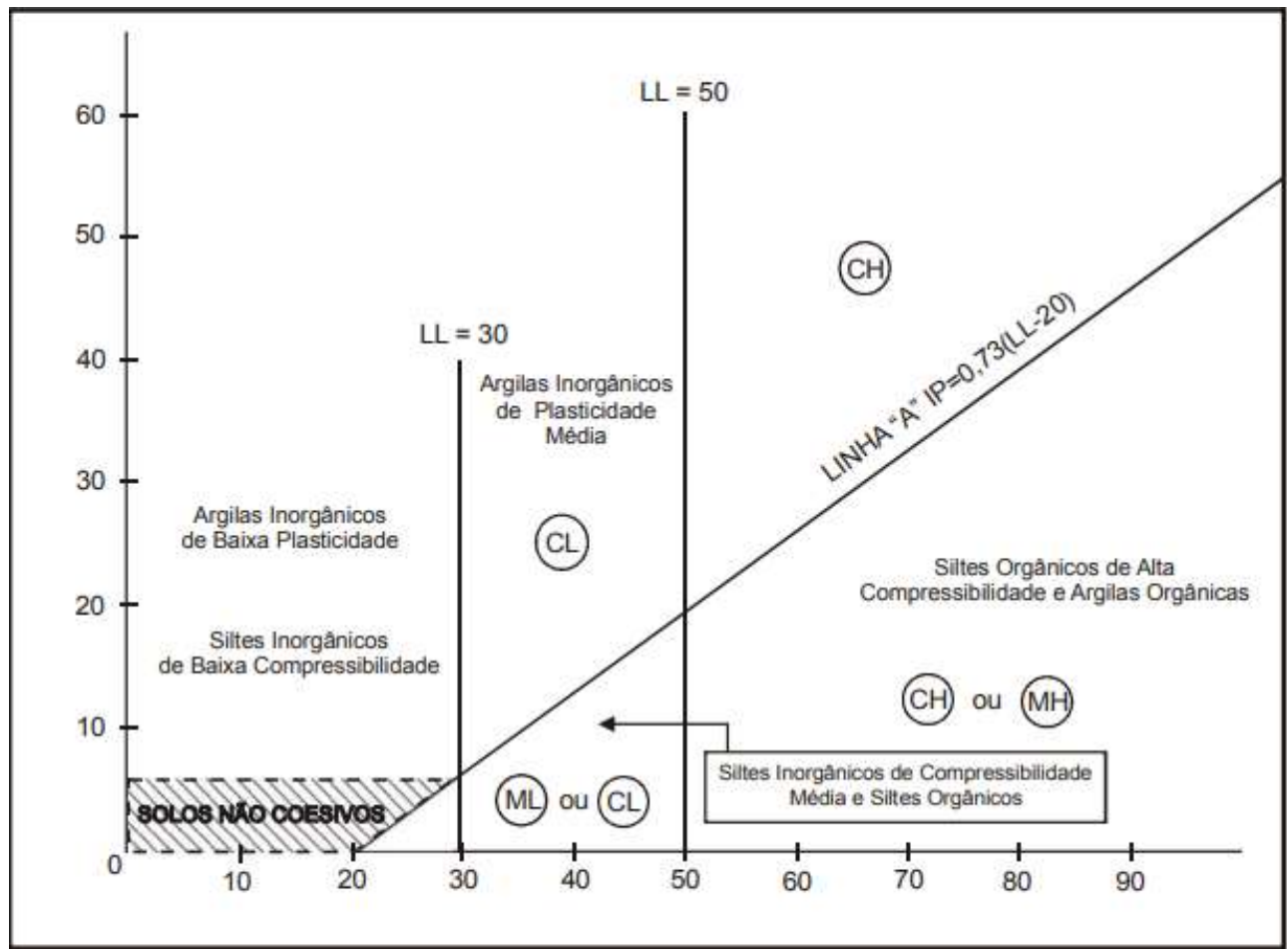

Figura 10: Gráfico de Plasticidade. Fonte: DNIT (2006).

Tabela 3: porcentagem de finos.

ABNT NBR 6502/95

\begin{tabular}{|c|c|c|c|c|c|c|c|}
\hline Argila & Silte & Areia & & & Pedregulho & Pedra & Matacãc \\
\hline $22,20 \%$ & $8,30 \%$ & Fina $16,8 \%$ & Média 41,4 & Grossa $11,2 \%$ & $0,10 \%$ & $0 \%$ & $0 \%$ \\
\hline
\end{tabular}

\section{Determinação de espessuras do pavimento}

A espessura mínima do revestimento recomendada para o fluxo de tráfego atual da rodovia, encontrada por meio do número equivalente de operações conforme Tabela 4 é de $12,5 \mathrm{~cm}$, recomenda-se esse valor para proteger a base dos impactos gerados pelo tráfego ou até mesmo a evitar rupturas no revestimento ocasionada pelos esforços repetitivos a tração e flexão. 0 material que compõe a base estabilizada para um pavimento flexível segundo as especificações do DNIT deve apresentar ISC superior ou 
igual a 60 para qualquer tipo de tráfego, exceto em casos de justificativas de carências de materiais mais nobres prevendo a redistribuição em outras camadas do pavimento, no entanto, a camada deve ter um CBR de no mínimo 40, além de apresentar uma expansão de até 0,5\%.

De acordo com as especificações técnicas para pavimentação a sub-base estabilizada granulometricamente deve ter um Índice de Suporte de Califórnia - ISC maior ou igual a 20 e IG igual a zero independentemente do tipo de tráfego. Nas visitas em campo verificamos também a existência de contaminação da base com a sub-base e desta com o subleito, o que caracteriza falha na execução da compactação ou excesso de filler como material de enchimento.

Tabela 4: número equivalente de operações.

\begin{tabular}{lll}
\hline DESCRIÇÃO & RESULTADOS \\
\hline Fator Climático Regional - FR & 1,4 & - \\
\hline Porcentagem de tráfego no sentido dominante - D & 53,7 & $\%$ \\
\hline Taxa de crescimento linear - t & 5 & $\%$ \\
\hline Período de Projeto - P & 10 & anos \\
\hline Volume inicial - Vo & 615,1 & - \\
\hline Volume do primeiro ano - V1 & 645,9 & - \\
\hline Volume do último ano de projeto - Vp & 968,8 & - \\
\hline Volume médio diário - VM & 807,4 & - \\
\hline número equivalente de operações - N & $3,43 \mathrm{E}+08$ & - \\
\hline Índice de Suporte Califórnia - CBR (Subleito) & 4 & $\%$ \\
\hline Índice de Suporte Califórnia - CBR (Base) & 17 & $\%$ \\
\hline Altura total do pavimento - Hm & 75,5 & $\mathrm{~cm}$ \\
\hline IS=CBR & 4 & $\%$ \\
\hline Coeficiente de equivalência estrutural - K (revestimento) & 2 \\
\hline Coeficiente de equivalência estrutural - K (demais camadas) & 1 & - \\
\hline
\end{tabular}

De acordo com o resultado demostrado na Tabela 5 do CBR da amostra da base que foi extraída do pavimento verificamos que a mesma não corresponde às características mínimas especificadas por normas, sendo este um fator importante para o dimensionamento das espessuras das camadas, que se não estiver de acordo com as especificações levam ao aparecimento de patologias.

Tabela 5: Ensaio mecânico.

\begin{tabular}{lcc}
\hline Subleito & \\
\hline Índice de Suporte Califórnia - CBR & 4 & $\%$ \\
\hline Expansão & 2 & $\%$ \\
\hline Base & 17 & $\%$ \\
\hline Índice de Suporte Califórnia - CBR & 2 & $\%$ \\
\hline Expansão & 2 & $\%$ \\
\hline
\end{tabular}

De posse do projeto original da TO 134, atual marginal oeste a BR 010 que foi disponibilizado pela Agência Tocantinense de Transporte e Obras-AGETO, a rodovia apresenta espessura do revestimento, base e sub-base de 3,5, 23 e $28 \mathrm{~cm}$ respectivamente como mostra a Figura 11, porém ao fazer o dimensionamento utilizando os critérios mínimos para o tráfego atual e das análises em laboratório como demostra a Tabela 5 supracitada, o pavimento deverá ter uma espessura total de aproximadamente $76 \mathrm{~cm}$ como mostra a Figura 12. 

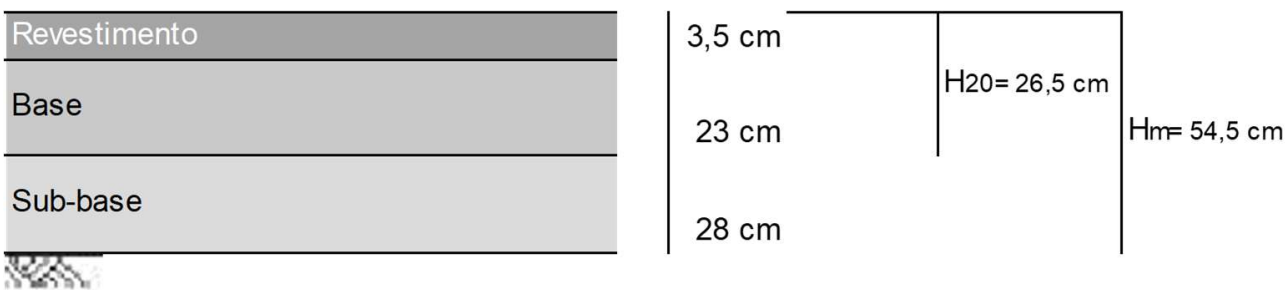

Subleito

Figura 11: Pavimento atual.

Segundo a AASHTO o solo apresenta característica de excelente a bom, porém no ensaio de CBR que mede a resistência a penetração, foi classificado como um material de baixa resistência, portanto este ensaio foi considerado para o dimensionamento do pavimento demostrado na Figura 12.

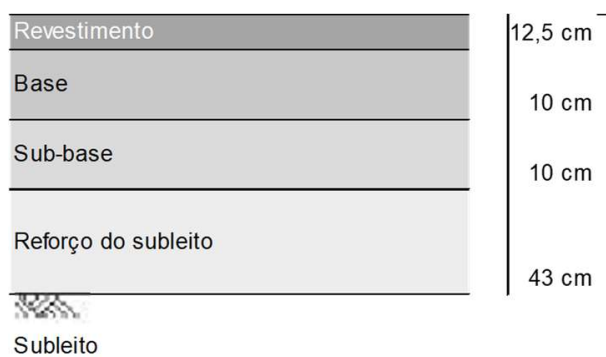

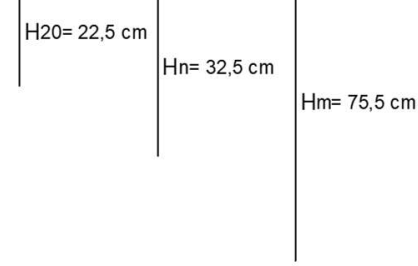

Figura 12: Dimensionamento do pavimento.

\section{DISCUSSÃO}

A falha no dimensionamento da rodovia estudada ocasionou uma série de manifestações patológicas, em praticamente todo o perímetro verifica-se a presença de desagregação, esse problema ocorre com a perda dos materiais graúdos ou finos da capa de rolamento, causada pelas trilhas de rodas devido ao desgaste pela ação do tráfego muito intenso na via (DER, 2012).

O defeito mencionado anteriormente também pode ocorrer devido a presença da água ou contaminação dos agregados que ocasiona a perda por adesão entre a mistura asfáltica e os agregados, ou até mesmo pela má exceção da camada de revestimento, utilizando uma camada muito fina não adequada para o fluxo, sendo que o mesmo deveria possuir uma espessura de $12,5 \mathrm{~cm}$ quanto na realidade possui apenas $3,5 \mathrm{~cm}$.

A ausência ou falha de manutenção e/ou conversação e a execução inadequada no processo de compactação podem acarretar diversos defeitos na via, como as trincas que posteriormente ocasionam trincas por fadiga gerando as panelas ou buracos, com presença desses defeitos o pavimento deixa de cumprir com os requisitos mínimos, economia e segurança aos usuários causado por acidentes. Nas vistas em campo foram constatados a ausência de espaçamentos de trezentos (300) metros entre panelas ou buracos com outras patologias, logo, não é recomendável a correção do serviço tapa-buraco.

A melhor forma de correção da via seria o redimensionamento do pavimento, sendo comprovado a necessidade de reforço do subleito, mas não sendo economicamente viável, necessariamente deve-se executar o recapeamento nos locais que não afetam a base ou sub-base. Para os trechos considerados mais 
críticos, isto é, que afetam além das camadas do revestimento há a necessidade da reconstrução de todo o trecho, caso isso não ocorra, o trecho continuará danificado, surgindo novos defeitos.

\section{CONCLUSÕES}

Com base nos parâmetros do projeto original e dos resultados analisados em laboratório e campo a presença de patologias encontrados no trecho estudado está relacionado com materiais de baixa qualidade, uma vez que o mesmo não corresponde as especificações mínimas determinada pelo DNIT. De acordo com ensaio de CBR para o subleito concluímos que haverá à necessidade de inclusão de uma camada de reforço do subleito, pois o mesmo não apresentou competência suficiente para resistir aos esforços a que será submetido.

O ensaio de CBR, que também foi um meio de análise da capacidade de resistência da base que compõe o pavimento é de baixa qualidade, não sendo suficiente para a estabilização da camada de base o que influencia na propagação de patologias em pavimentos flexíveis. Outro fator que levaram as manifestações patológicas foi a falha na execução das camadas da base e sub-base, na qual foi constatado a perda de materiais desses elementos, caracterizando grau de compactação insuficiente ou de forma inadequada.

Como foi constato a necessidade da camada do reforço do subleito e a contaminação e perda de materiais das camadas da base e sub-base, a alternativa mais eficaz para que o pavimento desempenhe sua função primordial seria a reconstrução do trecho estudado. Concluindo este estudo, é evidente a importância de planejamento, execução e utilização de materiais de boa qualidade, minimizando as manifestações patológicas, possibilitando assim mais conforto, segurança e economia aos usuários trafegam na via.

\section{REFERÊNCIAS}

ABNT. Associação Brasileira de Normas Técnicas. NBR 7207/1982: Terminologia e Classificação de Pavimentação. Rio de Janeiro: ABNT, 1982.

ABNT. Associação Brasileira de Normas Técnicas. NBR 6459/1982: Determinação do Limite de Liquidez. Rio de Janeiro: ABNT, 1982.

ABNT. Associação Brasileira de Normas Técnicas. NBR 6459/1982: Solo: Análise Granulométrica. Rio de Janeiro: ABNT, 1984

ABNT. Associação Brasileira de Normas Técnicas. NBR 6508/1984: Grãos de solos que passam na peneira de 4,8 $\mathrm{mm}$ : Determinação da massa específica. Rio de Janeiro: ABNT, 1984.
ABNT. Associação Brasileira de Normas Técnicas. NBR 7180/1982: Determinação do Limite de Plasticidade. Rio de Janeiro: ABNT, 1982

ABNT. Associação Brasileira de Normas Técnicas. NBR 7182/1988: Solo: Ensaio de Compactação. Rio de Janeiro: ABNT, 1988.

ABNT. Associação Brasileira de Normas Técnicas. NBR 9895/2017: Solo: Índice de suporte Califórnia (ISC): Método de ensaio. Rio de Janeiro: ABNT, 2017.

DER. Departamento de Estradas de Rodagem do Estado de São Paulo. Manual Básico De Estradas E Rodovias Vicinais. 2 ed. São Paulo, 2012

DNIT. Departamento Nacional de Infraestrutura de Transporte. Manual De Pavimentação. 3 ed. Rio de Janeiro, 2006.

A CBPC - Companhia Brasileira de Produção Científica (CNPJ: 11.221.422/0001-03) detém os direitos materiais desta publicação. Os direitos referem-se à publicação do trabalho em qualquer parte do mundo, incluindo os direitos às renovações, expansões e disseminações da contribuição, bem como outros direitos subsidiários. Todos os trabalhos publicados eletronicamente poderão posteriormente ser publicados em coletâneas impressas sob coordenação da Sustenere Publishing, da Companhia Brasileira de Produção Científica e seus parceiros autorizados. Os (as) autores (as) preservam os direitos autorais, mas não têm permissão para a publicação da contribuição em outro meio, impresso ou digital, em português ou em tradução. 